\title{
ANALISA WAKTU BAKU PRODUKSI DOMPET DENGAN PENDEKATAN PETA TANGAN KIRI DAN TANGAN KANAN PADA CV. XYZ DI PASURUAN
}

\author{
Hasan Bashori $^{1)}$, Roisyatul Umami ${ }^{2)}$ \\ ${ }^{1)}$ Dosen Teknik industri Fakultas Teknik Universitas Yudharta Pasuruan \\ ${ }^{2)}$ Mahasiswa Teknik industri Fakultas Teknik Universitas Yudharta Pasuruan
}

\begin{abstract}
Abstrak
Penelitian ini dilakukan pada CV. XYZ yang memproduksi dompet. Permasalahan yang terjadi adalah turunnya produktifitas perusahan yang disebabkan oleh pembuangan waktu yang sia-sia dalam melakukan pekerjaan. Oleh sebab itu dilakukan sebuah evaluasi metode kerja dengan pendekatan peta tangan kiri dan tangan kanan yang diharapkan dapat mengurangi pemborosan waktu dan menentukan waktu baku dalam melakukan aktifitas kerja proses produksi di perusahaan. Dari hasil analisa yang dilakukan, diketahui bahwa proses kerja diperusahaan saat ini untuk membuat 1 unit dompet membutuhkan waktu sebesar 69.35 menit. Sedangkan dengan proses kerja usulan dengan pendekatan peta tangan kiri dan tangan kanan untuk menghasilkan 1 unit dompet membutuhkan waktu sebesar 59.17 menit. Hasil perhitungan selisih waktu antara proses kerja diperusahaan saat ini dengan proses kerja usulan dengan pendekatan peta tangan kiri dan tangan kanan diperoleh penghematan waktu sebesar 10.18 menit, dengan prosentase penghematan waktu baku pada proses marking dan pemotongan sebesar $11.25 \%$, proses pengeleman sebesar $20.69 \%$ dan proses jahit sebesar $7.39 \%$, serta prosentase kenaikan output standart sebesar $21.43 \%$.
\end{abstract}

Kata kunci : waktu baku, peta tangan kiri dan tangan kanan.

\section{PENDAHULUAN}

Upaya peningkatan produktifitas dompet pada sebuah perusahan tidak terlepasdari faktor manusia. Hal ini dilakukan karena dari manusia dapat diharapakan untuk mendapatkan alternatif cara kerja yang baik, efektif, dan efisien.

Menurut Kharisma(2009), bahwa pengertian efektif berkaitan dengan cara kerja yang tepat serta waktu penyelesaian pekerjaan yang singkat. Sedangkanefisiensi berkaitan dengan meminimalkan biaya untuk menyelesaikan pekerjaan.

CV. XYZ merupakan perusahaan yang berlokasi didaerah Pasuruan dan bergerak dalam bidang pembuatan dompet. Dalam proses pembuatannya, antara lain:(1) proses marking sesuai dengan pola yang diinginkan; (2) bahan dipotong sesuai dengan garis marking, (3) upper diseset dan ditempel atau digabungkan dengan kain yang berbahan saten sebagai interlining;(4) sebelum dijahit bahan upper bagian depan diembos (top merk) terlebih dahulu untuk memberikan merk dengan variasi timbul; (5) bahan upper dijahit; (6) packing.

Sedangkan permasalahan yang terjadi pada CV. XYZ adalah kesalahan dalam metode kerja yang berdampak pada produktifitas perusahaan dan keterlambatan pengiriman barang. Hal ini dipengaruhi oleh keterlambatan produksi yang diakibatkan oleh pembuangan waktu yang sia-sia. Maka dari itu, evaluasi perancangan kerja harus dilakukan secara terus menerus untuk mendapatkan metode yang baik. Salah satu caradalam mengevaluasi metode kerja adalah dengan menggunakan peta kerja dan pengukuran 
waktu standar untuk menentukan waktu baku produksi.

Pengukuran waktu merupakan suatu pekerjaan mengamati pekerja dan mencatat waktu kerja, baik pada setiap elemen ataupun siklus dengan menggunakan alat-alat penghitung waktu (Sutalaksana dkk., 1997).

Studi waktu dapat dilakukan dengan menghitung waktu siklus, waktu normal, dan waktu baku. Perhitungan tersebut dengan cara mengukur waktu yang digunakan operator untuk menyelesaikan pekerjaan. Tujuan dari studi gerak dan waktuagar dapat meminimalkan gerakan-gerakan kerja yang tidak efektif sehingga akan diperoleh waktu kerja yang optimal.

Dalam penelitian ini, metode yang digunakan untuk mengevaluasi metode kerja dalam menentukan waktu baku produksi dompet adalah dengan pendekatanpeta tangan kiri dan tangan kanan.

\section{KERANGKA TEORI}

\section{Peta Tangan Kanan Dan Tangan Kiri}

Peta tangan kiri dan tangan kanan merupakan suatu peta yang menggambarkan semua gerakan-gerakan dan waktu mengangguryang dilakukan oleh tangan kiri dan tangan kanan pada saat berkerja.Selain itu, peta ini dapat menunjukkan perbandingan antara tugas yang dibebankan pada tangan kiri dan tangan kanan ketika dalam melakukan suatu aktividompet.

Tujuan dari peta tangan kiri dan tangan kanan adalah mengurangi gerakan-gerakan yang tidak perlu dilakukan dan mengatur gerakan pada proses bekerja, sehingga diperoleh urutan gerakan yang baik. Adanya peta tangan kiri dan tangan kanan diharapkan dapat mempermudah dalam menganalisa gerakan-gerakan yang dilakukan oleh seorang pekerja selama melakukan pekerjaannyadan semua operasi gerakanuntuk memperbaiki suatu gerakan pekerjaan yang bersifat manual.

Untuk mempermudah analisa kerja, maka dilakukan pembuatan peta operator yang diharapkan dapat membantu menganalisa gerakan yang terjadi berulang-ulang (repetitive) dan dilakukan secara manual (seperti dalam proses perakitan). Analisa yang dibuat dengan mengusulkan pola gerakan tangan yang dianggap tidak efisien dan bertentangan dengan prinsip-prinsip ekonomi gerakan (motion economy). Demikian pula diharapkan terjadi keseimbangan gerakan yang dilakukan oleh tangan kiri dan tangan kanan, sehingga siklus kerja dapat berlangsung dengan lancar dalam ritme gerakan yang lebih baik dan mampu memberikan delays maupun operator fatigue yang minimum.

Setelah peta operatorselesai dibuat, langkah selanjutnya menganalisis perbaikan agar gerakan kerja yang berlangsung lebih efektif dan efisien.Untuk mengetahui efisiensi waktu yang digunakan, dibuat persamaan sebagai berikut:

$$
h=\frac{B-A}{B} \times 100 \%
$$

Keterangan:

$\mathrm{h}=$ efisiensi waktu

$\mathrm{B}=$ waktu siklus awal

$\mathrm{A}=$ waktu siklus akhir

\section{Waktu Pengamatan (Waktu Siklus)}

Waktu pengamatan merupakan waktu yang diperoleh dari hasil pengamatan dan 
pengukuran waktu yang diperlukan oleh pekerja untuk menyelesaikan sebuah pekerjaan. Rumus yang digunakan untuk menghitung waktu siklus (Sritomo Wignjoseobroto, 2003):

$$
\text { Waktu siklus rata-rata }=\frac{\sum X i}{N}
$$

\section{Keterangan:}

$\sum \mathrm{Xi}=$ Jumlah waktu siklus

$\mathrm{N}=$ Jumlah Pengamatan

\section{Waktu Normal}

Waktu normal disini tidak termasuk waktu longgar yang diperlukan untuk melepas lelah (fatique) ataupun kebutuhan seorang pekerja (personalneeds). Rumus yang digunakan untuk menghitung waktu normal (Sritomo Wignjoseobroto, 2003):

Waktu Normal $(\mathrm{WN})=$ Waktu Siklus $\mathrm{x}$ PerformanceRating (\%)

\section{StandardTime (Waktu Baku)}

Waktu baku merupakan waktu yang dibutuhkan oleh pekerja untuk menyelesaikan suatu pekerjaan. Waktu baku ini sudah mencapai kelonggaran waktu (allowancetime). Waktu kelonggaran merupakan kelonggaran yang diberikan untuk menghilangkan rasa fatique dan hambatan-hambatan yang tidak dapat dihindarkan. Rumus yang digunakan untuk menghitung waktu baku (Sritomo Wignjoseobroto, 2003):

$$
\text { WaktuBaku }=\text { Waktunormal }
$$

$$
\times \frac{100 \%}{100 \%-\% \text { allowance }}
$$

Keterangan:

Allowance $=$ Kelonggaran

METODE PENELITIAN
Dalam kegiatan penelitian, metode dapat diartikan sebagai cara atau prosedur yang harus ditempuh untuk menjawab masalah penelitian.Prosedur penelitian merupakan langkah kerja yang bersifat sistematis, mulai dari perencanaan, pelaksanaan, dan pengambilan kesimpulan (Suryabrata, 2013).

Dalampenelitian ini menggunakan metode kuantitatif untuk mengola data-data yang diperoleh dari lokasi penelitian yang berupa data skunder maupun data primer.

\section{Rancangan Penelitian}

Jenis rancangan penelitian yang dilakukan menggunakan deskriptif kuantitatif yang dilakukan melalui metode survei untuk mengumpulkan serta menganalisa datadalam tanya jawab dan wawancara (Suryabrata, 2013).

Tahapan penelitian dalam perancangan suatu alat dan perhitungan waktu baku secara garis besar dilakukan dalam dua tahap:

a) Tahapan pertama, merupakan penelitian yang bersifat kuantitatif mempunyai tujuan verifikasi teori, meletakkan teori secara dedukatif menjadi landasan pemecahan masalah penelitian serta instrumen dalam hal ini adalah wawancara dan praktek kerja langsung untuk mengukur tingkat kompetensi yang dimiliki oleh pekerja dan disesuaikan dengan kondisi perusahaan. Kemudian hasil penelitian tersebut dianalisa dan menghasilkan data diskriptif berupa perbandingan kuantitatif.

b) Tahap kedua, penelitian lebih mencerminkan sifat kualitatif karena peneliti setelah melakukan proses wawancara sebagai sarana pengumpulan 
data dan informasi kemudian mendiskusukan kepada pihak manajerial .proses ini dilakukan dengan tujuan menyusun teori melalui pengungkapan fakta yang dalam hal ini berupa alat kerja dan waktu baku kerja.

HASIL

PENELITIAN

DAN

\section{PEMBAHASAN}

\section{Pengukuran Waktu kerja Sekarang}

Pengumpulan data gerakan kerja dan waktu kerja dilakukan dengan cara survey lokasi. Setelah itu data yang sudah ada diuraikan berdasarkan gerakan kerja dan dihitung waktunya dengan menggunakan stopwacth. Data yang akan dihitung ini berdasarkan komponen-komponen kerja yang ada. Dengan data yang sudah terkumpul, maka dapat diketahui waktu prosesnya sebagai berikut:

1. Waktu baku marking dan pemotongan bahan

Tabel 1. Siklus Pengamatan Proses Marking dan Pemotongan Bahan

\begin{tabular}{|c|c|c|c|c|c|c|c|c|}
\hline \multirow{2}{*}{ Proses } & \multicolumn{5}{|c|}{ Siklus Pengamatan } & & $\begin{array}{c}\text { Rata-rata } \\
\text { waktu } \\
\text { siklus }\end{array}$ \\
\cline { 2 - 8 } & 1 & 2 & 3 & 4 & 5 & 6 & Total & \\
\hline $\begin{array}{c}\text { Marking dan } \\
\text { Potong (x) }\end{array}$ & 15.01 & 15.11 & 15.05 & 15.02 & 15.05 & 15.02 & 90,3 & 15.04 \\
\hline
\end{tabular}

Sumber: Hasil Pengolahan Data

- Uji keseragaman data

Standart deviasi $(\sigma)$

$\sigma=\sqrt{\frac{n\left(\sum X_{i}^{2}\right)-\left(\sum X\right)^{2}}{n(n-1)}}$

$\sigma=\sqrt{\frac{6(1357,82)-(90.26)^{2}}{6(6-1)}}$

$=0.037$

$\mathrm{BKA}=\bar{X}+2 \sigma \quad \mathrm{BKB}=\bar{X}-2 \sigma$

$=15.04+2(0.037) \quad=15.04-2(0.037)$
$=15.11$ menit $\quad=14.97$ menit

Dari pengamatan waktu rata-rata pada proses marking dan pemotongan kerja sebelum usulan perbaikan adalah 15.04 menit dan rating performance operator $10 \%$ dan allowance selama 7 jam kerja sebesar 13\%, maka:

- Waktu normal

$$
\begin{aligned}
\mathrm{Wn} & =\mathrm{Ws} \times \mathrm{fp} \\
& =100 \%+10 \% \\
& =1,1 \\
\mathrm{Wn} & =15.04 \times 1.1 \\
& =16.544
\end{aligned}
$$

- Waktu baku

$$
\begin{aligned}
\mathrm{Wb} & =\mathrm{Wn} \times \frac{100 \%}{100 \%-\% \text { allowance }} \\
& =16.544 \times \frac{100 \%}{100 \%-13 \%} \\
& =19.03 \text { menit }
\end{aligned}
$$

- Output Standart

$$
\begin{aligned}
\text { Os } & =\frac{1}{\mathrm{~Wb}} \\
& =\frac{1}{19.03} \\
& =0.05 \text { unit } / \text { menit }
\end{aligned}
$$

2. Waktu baku proses seset bahan

Tabel 2. Siklus Pengamatan Proses Seset

\begin{tabular}{|c|c|c|c|c|c|c|c|c|}
\hline \multirow{2}{*}{ Proses } & \multicolumn{5}{|c|}{ Siklus Pengamatan } & & $\begin{array}{c}\text { Rata-rata } \\
\text { waktu } \\
\end{array}$ \\
\cline { 2 - 7 } & 1 & 2 & 3 & 4 & 5 & 6 & Total & siklus \\
\hline & & & & & & & & \\
Seset (x) & 3.03 & 3.08 & 3.09 & 3.02 & 3.03 & 3.03 & 18.28 & 3.04 \\
\hline
\end{tabular}

Sumber: Hasil Pengolahan Data

- Uji keseragaman data

Standart deviasi $(\sigma)$

$$
\sigma=\sqrt{\frac{n\left(\sum X_{i}^{2}\right)-\left(\sum X\right)^{2}}{n(n-1)}}
$$




$$
\begin{aligned}
& \sigma=\sqrt{\frac{6(55.70)-(18.28)^{2}}{6(6-1)}} \\
& =0.03
\end{aligned}
$$

$$
\begin{array}{ll}
\text { BKA }=\bar{X}+2 \sigma & \text { BKB }=\bar{X}-2 \sigma \\
=3.04+2(0.03) & =3.04-2(0.03) \\
=3.10 \text { menit } & =2.98 \text { menit }
\end{array}
$$

Dari pengamatan waktu rata-rata pada proses seset sebelum usulan perbaikan adalah 3.04 menit dan rating performance operator $10 \%$ dan allowance selama 7 jam kerja sebesar 13\%, maka:

- Waktu normal

$$
\begin{aligned}
\text { Wn } & =\text { Ws } \times \mathrm{fp} \\
\mathrm{fp} & =100 \%+10 \% \\
=1,1 & \\
\mathrm{Wn} & =3.04 \times 1.1 \\
& =3.34 \text { menit }
\end{aligned}
$$

- Waktu baku

$$
\begin{aligned}
& \mathrm{Wb}=\mathrm{Wn} \times \frac{100 \%}{100 \%-\% \text { allowance }} \\
= & 3.34 \times \frac{100 \%}{100 \%-13 \%} \\
= & 3.84 \mathrm{menit} / \text { unit }
\end{aligned}
$$

- OutputStandart

$$
\begin{aligned}
\text { Os }=\frac{1}{\mathrm{~Wb}} \\
=\frac{1}{3.84} \\
=0.26 \mathrm{unit} / \mathrm{menit}
\end{aligned}
$$

3. Waktu baku proses pengeleman

Tabel 3. Siklus Pengamatan Proses Pengeleman Bahan

\begin{tabular}{|c|c|c|c|c|c|c|c|c|}
\hline & \multicolumn{5}{|c|}{ Siklus Pengamatan } & & $\begin{array}{c}\text { Rata-rata } \\
\text { waktu } \\
\text { Piklus }\end{array}$ \\
\cline { 2 - 7 } & 1 & 2 & 3 & 4 & 5 & 6 & Total & sikes \\
\hline Pengeleman & 29.41 & 29.46 & 29.45 & 29.40 & 29.43 & 29.41 & 176.56 & 29.42 \\
\hline
\end{tabular}

Sumber: Hasil Pengolahan Data
Standart deviasi $(\sigma)$

$$
\begin{aligned}
\sigma & =\sqrt{\frac{n\left(\sum X_{i}^{2}\right)-\left(\sum X\right)^{2}}{n(n-1)}} \\
\sigma & =\sqrt{\frac{6(5195.58)-(176.56)^{2}}{6(6-1)}} \\
& =0.024
\end{aligned}
$$

$\mathrm{BKA}=\bar{X}+2 \sigma$ $\mathrm{BKB}=\bar{X}-2 \sigma$

$=29.42+2(0.024)$ $=29.42-$ 2(0.024) $=29.47$ menit $=29.37$ menit

Dari pengamatan waktu rata-rata pada proses seset sebelum usulan perbaikan adalah 29.42 menit dan rating performance operator $10 \%$ dan allowance selama 7 jam kerja sebesar 13\%, maka:

- Waktu normal

$$
\begin{aligned}
\mathrm{Wn} & =\mathrm{Ws} \times \mathrm{fp} \\
\mathrm{fp} & =100 \%+10 \% \\
=1,1 & \\
\mathrm{Wn} & =29.42 \times 1.1 \\
& =32.36 \text { menit }
\end{aligned}
$$

- Waktu baku

$$
\begin{aligned}
\mathrm{Wb} & =\mathrm{Wn} \times \frac{100 \%}{100 \%-\% \text { allowance }} \\
& =32.36 \times \frac{100 \%}{100 \%-13 \%}
\end{aligned}
$$

$=37.21 \mathrm{menit} / \mathrm{unit}$

- OutputStandart

$$
\begin{aligned}
& \text { Os }=\frac{1}{\mathrm{~Wb}} \\
= & \frac{1}{37.21} \\
= & 0.03 \text { unit } / \text { menit }
\end{aligned}
$$

4. Waktu baku proses topmerk

- Uji keseragaman data 
Tabel 4. Siklus Pengamatan Proses TopMerk

\begin{tabular}{|c|c|c|c|c|c|c|c|c|}
\hline \multirow{2}{*}{ Proses } & \multicolumn{5}{|c|}{ Siklus Pengamatan } & \multirow{2}{*}{ Total } & Rata-rata \\
\cline { 2 - 6 } & 1 & 2 & 3 & 4 & 5 & 6 & & waktu siklus \\
\hline $\begin{array}{c}\text { Top } \\
\text { Merk }\end{array}$ & 3.71 & 3.67 & 3.70 & 3.70 & 3.69 & 3.70 & 22.17 & 3.69 \\
\hline
\end{tabular}

Sumber: Hasil Pengolahan Data

- Uji keseragaman data

Standart deviasi $(\sigma)$

$$
\begin{aligned}
\sigma & =\sqrt{\frac{n\left(\sum X_{i}^{2}\right)-\left(\sum X\right)^{2}}{n(n-1)}} \\
\sigma & =\sqrt{\frac{6(81.92)-(22.17)^{2}}{6(6-1)}} \\
& =0.014
\end{aligned}
$$

$$
\begin{array}{ll}
\text { BKA }=\bar{X}+2 \sigma & \text { BKB }=\bar{X}-2 \sigma \\
=3.69+2(0.014) & =3.69-2(0.014) \\
=3.72 \text { menit } & =3.66 \text { menit }
\end{array}
$$

Dari pengamatan waktu rata-rata pada proses seset sebelum usulan perbaikan adalah 3.69 menit dan rating performance operator $10 \%$ dan allowance selama 7 jam kerja sebesar $13 \%$, maka:

- Waktu normal

$$
\begin{aligned}
& \text { Wn }=\text { Ws x fp } \\
& \text { fp }=100 \%+10 \% \\
& \begin{aligned}
=1,1 & \\
\mathrm{Wn} \quad= & 3.69 \times 1.1 \\
= & 4.06 \text { menit }
\end{aligned}
\end{aligned}
$$

\begin{tabular}{|c|c|c|c|c|c|c|c|c|}
\hline \multirow{2}{*}{ Proses } & \multicolumn{6}{|c|}{ Siklus Pengamatan } & \multirow[b]{2}{*}{ Total } & \multirow{2}{*}{$\begin{array}{c}\text { Rata-rata } \\
\text { waktu siklus }\end{array}$} \\
\hline & 1 & 2 & 3 & 4 & 5 & 6 & & \\
\hline Jahit & 3.63 & 3.64 & 3.63 & 3.60 & 3.65 & 3.6 & 21.78 & 3.63 \\
\hline
\end{tabular}

- Waktu baku

$$
\begin{aligned}
\mathrm{Wb}=\mathrm{Wn} \times & \frac{100 \%}{100 \%-\% \text { allowance }} \\
& =4.06 \times \frac{100 \%}{100 \%-13 \%}
\end{aligned}
$$

$=4.67 \mathrm{menit} / \mathrm{unit}$

- OutputStandart

$$
\text { Os }=\frac{1}{\mathrm{~Wb}}
$$

$=\frac{1}{4.67}$

$=0.21 \mathrm{unit} / \mathrm{menit}$

5. Waktu baku proses jahit

Tabel 5. Siklus Pengamatan Proses Jahit

Sumber: Hasil Pengolahan Data

- Uji keseragaman data

Standart deviasi $(\sigma)$

$$
\begin{aligned}
\sigma & =\sqrt{\frac{n\left(\sum X_{i}^{2}\right)-\left(\sum X\right)^{2}}{n(n-1)}} \\
\sigma & =\sqrt{\frac{6(79.06)-(21.78)^{2}}{6(6-1)}} \\
& =0.017
\end{aligned}
$$

$$
\begin{array}{llrl}
\text { BKA }=\bar{X}+2 \sigma & \mathrm{BKB} & =\bar{X}-2 \sigma \\
& =3.63+2(0.017) & & =3.63-2(0.017) \\
& =3.66 \text { menit } & & =3.59 \text { menit }
\end{array}
$$

Dari pengamatan waktu rata-rata pada proses seset sebelum usulan perbaikan adalah 3.63 menit dan rating performance operator $10 \%$ dan allowance selama 7 jam kerja sebesar 13\% , maka:

- Waktu normal

$$
\mathrm{Wn}=\mathrm{Ws} \times \mathrm{fp}
$$

$$
\begin{aligned}
\mathrm{fp} & =100 \%+10 \% \\
& =1,1 \\
\mathrm{Wn} & =3.63 \times 1.1 \\
& =4.0 \text { menit }
\end{aligned}
$$

- Waktu baku

$$
\mathrm{Wb}=\mathrm{Wn} \times \frac{100 \%}{100 \%-\% \text { allowance }}
$$




$$
\begin{aligned}
& =4.0 \times \frac{100 \%}{100 \%-13 \%} \\
& =4.6 \text { menit/unit }
\end{aligned}
$$

- OutputStandart

$$
\begin{aligned}
\text { Os } & =\frac{1}{\mathrm{~Wb}} \\
=\frac{1}{4.6} & \\
& =0.21 \mathrm{unit} / \text { menit } \\
& \text { Dari data perhitungan yang telah }
\end{aligned}
$$
dilakukan, dapat diketahui bahwa waktu baku dalam proses marking dan pemotongan sebesar 19.03 menit dengan output standart sebesar 0.05 unit/menit, waktu baku dalam proses seset sebesar 3.84 menit dengan output standart sebesar 0.26 unit/menit, waktu baku dalam proses pengeleman sebesar 37.21 menit dengan output standart sebesar 0.03 unit/menit, waktu baku dalam proses top merk sebesar 4.67 menit dengan output standart sebesar 0.21 unit/menit, dan untuk waktu baku dalam proses jahit sebesar 4.6 menit dengan output standart sebesar 0.21 unit/menit. Maka ketika dijumlah akan diketahui proses produksi pembuatan dompet adalah sebesar 69.35 menit untuk menghasilkan 1 unit dompet.

\section{Usulan PengukuranWaktu Kerja Proses

\begin{tabular}{|c|c|c|c|c|c|c|c|c|}
\hline \multirow{2}{*}{ Proses } & \multicolumn{6}{|c|}{ Siklus Pengamatan } & \multirow[b]{2}{*}{ Total } & \multirow{2}{*}{$\begin{array}{r}\text { Rata-rata } \\
\text { waktu siklus }\end{array}$} \\
\hline & 1 & 2 & 3 & 4 & 5 & 6 & & \\
\hline $\begin{array}{c}\text { Marking } \\
\text { dan }\end{array}$ & 13.35 & 13.37 & 13.35 & 13.33 & 13.36 & 13.35 & 80.11 & \\
\hline Potong & & & & & & & & 13.35 \\
\hline
\end{tabular} Pembuatan Dompet}

1. Waktu baku prosesmarking dan pemotongan bahan

Tabel 6. Pengamatan waktu pada proses marking dan pemotongan bahan setelah usulan

Sumber: Hasil Pengolahan Data
- Uji keseragaman data

Standart deviasi $(\sigma)$

$$
\begin{aligned}
\sigma & =\sqrt{\frac{n\left(\sum X_{i}^{2}\right)-\left(\sum X\right)^{2}}{n(n-1)}} \\
\sigma & =\sqrt{\frac{6(1069.60)-(80.11)^{2}}{6(6-1)}} \\
& =0.014
\end{aligned}
$$

$\mathrm{BKA}=\bar{X}+2 \sigma \quad \mathrm{BKB}=\bar{X}-2 \sigma$

$=13.35+2(0.014) \quad=13.35-2(0.014)$

$=13.38$ menit $\quad=13.32$ menit

Dari pengamatan waktu rata-rata pada proses marking dan pemotongankerja sebelum usulan perbaikan adalah 13.35 menit dan rating performance operator $10 \%$ dan allowance selama 7 jam kerja sebesar 13\%, maka:

- Waktu normal

$$
\mathrm{Wn}=\mathrm{Ws} \times \mathrm{fp}
$$

$$
\begin{array}{ll}
\text { fp } & =100 \%+10 \% \\
& =1,1 \\
\text { Wn } & =13.35 \times 1.1 \\
& =14.69
\end{array}
$$

- Waktu baku

$$
\begin{array}{r}
\mathrm{Wb}=\mathrm{Wn} \times \frac{100 \%}{100 \%-\% \text { allowance }} \\
=14.69 \times \frac{100 \%}{100 \%-13 \%} \\
=16.89 \text { menit }
\end{array}
$$

- Output Standart

$$
\begin{aligned}
& \text { Os }=\frac{1}{\mathrm{~Wb}} \\
&= \frac{1}{16.89} \\
&= 0.05 \text { unit/menit } \\
& \text { 2. Waktu baku proses seset bahan }
\end{aligned}
$$


Pada proses seset waktu baku tetap seperti yang ada diperusahaan sekarang. Karena tidak ada usulan gerakan. Jadi waktu bakunya 3.84 menit/unit dengan output standart 0.26 unit/menit.

3. Waktu baku proses pengeleman

Tabel 7. Siklus Pengamatan Proses Pengeleman Bahan

\begin{tabular}{|c|c|c|c|c|c|c|c|c|}
\hline \multirow{2}{*}{ Proses } & \multicolumn{5}{|c|}{ Sikhs Pengamatan } & \multirow{2}{*}{ Rata-rata } \\
\cline { 2 - 6 } & 1 & 2 & 3 & 4 & 5 & 6 & Total & waktu sikkus \\
\hline Pengeleman & 23.35 & 23.32 & 23.34 & 23.34 & 23.35 & 23.31 & 140.01 & 24.31 \\
\hline
\end{tabular}

Sumber: Hasil Pengolahan Data

- Uji keseragaman data

Standart deviasi $(\sigma)$

$$
\begin{aligned}
\sigma & =\sqrt{\frac{n\left(\sum X_{i}^{2}\right)-\left(\sum X\right)^{2}}{n(n-1)}} \\
\sigma & =\sqrt{\frac{6(3267,14)-(140.01)^{2}}{6(6-1)}} \\
& =0.016
\end{aligned}
$$

$\mathrm{BKA}=\bar{X}+2 \sigma \quad \mathrm{BKB}=\bar{X}-2 \sigma$

$$
\begin{array}{rr}
=24.31+2(0.016) & =24.31-2(0.016) \\
=24.34 \text { menit } & =24.28 \text { menit }
\end{array}
$$

Dari pengamatan waktu rata-rata pada proses seset sebelum usulan perbaikan adalah 24.31 menit dan rating performance operator 10\% dan allowance selama 7 jam kerja sebesar 13\%, Maka:

- Waktu normal

$$
\begin{aligned}
& \mathrm{Wn}=\mathrm{Ws} \times \mathrm{fp} \\
& \mathrm{fp} \quad=100 \%+10 \% \\
&=1,1 \\
& \mathrm{Wn} \quad=23.34 \times 1.1 \\
&=25.66 \text { menit }
\end{aligned}
$$

- Waktu baku

$$
\mathrm{Wb}=\mathrm{Wn} \times \frac{100 \%}{100 \%-\% \text { allowance }}
$$

$$
\begin{gathered}
=25.66 \times \frac{100 \%}{100 \%-13 \%} \\
=29.51 \text { menit/unit }
\end{gathered}
$$

\section{- OutputStandart}

$$
\begin{aligned}
& \text { Os }=\frac{1}{\mathrm{~Wb}} \\
= & \frac{1}{29.51} \\
= & 0.03 \text { unit } / \text { menit }
\end{aligned}
$$

4. Waktu baku proses topmerk

Pada proses topmerktidak ada waktu baku usulan, karena tidak ada gerakan yang diusulkan. Maka waktu baku sesuai dengan yang ada diperusahaan yaitu waktu baku 4.67 menit/unit dengan output standar 0.21 unit/menit.

5. Waktu baku proses jahit

Tabel 8. Siklus Pengamatan Proses Jahit

\begin{tabular}{|c|c|c|c|c|c|c|c|c|}
\hline \multirow{2}{*}{ Proses } & \multicolumn{5}{|c|}{ Sikkus Pengamatan } & \multirow{2}{*}{ Rata-rata } \\
\cline { 2 - 7 } & 1 & 2 & 3 & 4 & 5 & 6 & Total \\
waktu sikkus \\
\hline Jahit & 3.36 & 3.33 & 3.36 & 3.36 & 3.38 & 3.37 & 20.16 & 3.36 \\
\hline
\end{tabular}
Sumber: Hasil Pengolahan Data

- Uji keseragaman data

Standart deviasi $(\sigma)$

$$
\sigma=\sqrt{\frac{n\left(\sum X_{i}^{2}\right)-\left(\sum X\right)^{2}}{n(n-1)}}
$$

$$
\begin{aligned}
\sigma & =\sqrt{\frac{6(67.74)-(20.16)^{2}}{6(6-1)}} \\
& =0.017
\end{aligned}
$$

$$
\begin{array}{lr}
\text { BKA }=\bar{X}+2 \sigma & \text { BKB }=\bar{X}-2 \sigma \\
=3.36+2(0.017) & =3.36-2(0.017) \\
=3.39 \text { menit } & =3.33 \text { menit }
\end{array}
$$

Dari pengamatan waktu rata-rata pada proses seset sebelum usulan perbaikan adalah 
3.36 menit dan rating performance operator $10 \%$ dan allowance selama 7 jam kerja sebesar 13\%, maka:

- Waktu normal

$$
\begin{aligned}
\text { Wn } & =\text { Ws } \times \mathrm{fp} \\
\mathrm{fp} & =100 \%+10 \% \\
=1,1 & \\
\mathrm{Wn} & =3.36 \times 1.1 \\
& =3.7 \text { menit }
\end{aligned}
$$

- Waktu baku

$$
\begin{aligned}
& \mathrm{Wb}=\mathrm{Wn} x \frac{100 \%}{100 \%-\% \text { allowance }} \\
&=3.7 \times \frac{100 \%}{100 \%-13 \%} \\
&=4.26 \mathrm{menit} / \mathrm{unit}
\end{aligned}
$$

- OutputStandart

$$
\text { Os }=\frac{1}{\mathrm{~Wb}}
$$

$$
=\frac{1}{4.26}
$$

$=0.23 \mathrm{unit} / \mathrm{menit}$

Setelah dilakukan perhitungan waktu kerja dengan metode usulan, maka waktu baku yang diperoleh dalam proses marking dan pemotongan sebesar 16.89 menit dengan outputstandart sebesar 0.05 unit/menit, waktu baku proses seset sebesar 3.84 menit dengan outputstandart sebesar 0.26 unit/menit, waktu baku proses pengeleman sebesar 29.51 menit dengan outputstandart sebesar 0.03 unit/menit, waktu baku proses topmerk sebesar 4.67 menit dengan outputstandart sebesar 0.21 unit/menit, dan waktu baku dalam proses jahit sebesar 4.26 menit dengan outputstandart sebesar 0.23 unit/menit. Ketika dijumlah akan diketahui proses produksi pembuatan dompet adalah sebesar 59.17 menit untuk menghasilkan 1 unit

\begin{tabular}{|c|c|c|c|c|}
\hline $\mathrm{NO}$ & PROSES & $\begin{array}{l}\text { WAKTU } \\
\text { LAMA } \\
\text { (menit) }\end{array}$ & $\begin{array}{c}\text { WAKTU } \\
\text { USULAN } \\
\text { (menit) }\end{array}$ & SELISIH \\
\hline 1 & $\begin{array}{l}\text { Marking dan } \\
\text { pemotongan } \\
\text { bahan }\end{array}$ & 19.03 & 16.89 & 2.14 \\
\hline 2 & Seset bahan & 3.84 & 3.84 & 0 \\
\hline 3 & Pengeleman & 37.21 & 29.51 & 7.7 \\
\hline 4 & Top merk & 4.67 & 4.67 & 0 \\
\hline 5 & Jahit & 4.60 & 4.26 & 0.34 \\
\hline & Total & 69.35 & 59.17 & 10.18 \\
\hline
\end{tabular}
dompet.

\section{Perhitungan Selisih dan Porsentase Waktu}

\section{Baku dan OutputStandart}

Diketahui waktu baku pada proses lama adalah 69.35 menit dan waktu baku pada proses usulan adalah 59.48 menit. Maka untuk mengetahui selisih waktu baku proses lama dan usulan adalah sebagai berikut:

Tabel 9. Selisih perhitungan waktu baku

a. Prosentase waktu baku marking dan pemotongan bahan

$$
=\frac{\text { Hasil pengurangan waktu baku }}{\text { Waktu baku lama }} \times 100 \%
$$

$=\frac{2.14 \text { menit }}{19.03 \text { menit }} \times 100 \%$

$=11.25 \%$

b. Prosentase waktu baku proses seset bahan $=$ $0 \%$

c. Prosentase waktu baku proses pengeleman bahan

$=\frac{\text { Hasil pengurangan waktu baku }}{\text { Waktu baku lama }} \times 100 \%$

$=\frac{7.7 \text { menit }}{37.21 \text { menit }} \times 100 \%$

$=20.69 \%$

d. Prosentase waktu baku proses topmerk bahan $=0 \%$ 
e. Prosentase waktu baku proses jahit bahan

$=\frac{\text { Hasil pengurangan waktu baku }}{\text { Waktu baku lama }} \times 100 \%$

$=\frac{0.34 \text { menit }}{4.60 \text { menit }} \times 100 \%$

$=7.39 \%$

\section{Prosentase Output Standart}

(Os) Proses lama $=1 / 69.35=0.014$ unit $/$ menit

(Os) Proses usulan=1/59.17 $=0.017$ unit $/$ menit

- Prosentase Kenaikan Os

$$
=\frac{\text { Os baru-Os lama }}{\text { Os lama }} \times 100 \%
$$

$=\frac{0.017-0.014}{0.014} \times 100 \%$

$=21.43 \%$

Dari hasil perhitungan selisih waktu baku anta proses kerja lama dengan usulan, maka diperoleh penghematan waktu baku dengan selisih waktu sebesar 10.18 menit dengan porsentase kenaikan outputstandart adalah $21.43 \%$.

\section{KESIMPULAN DAN SARAN}

Dari hasil penelitian yang telah dilakukan, dapat diketahui bahwa proses kerja diperusahaan saat ini untuk membuat 1 unit dompet membutuhkan waktu sebesar 69.35 menit. Sedangkan dengan proses kerja usulan dengan pendekatan peta tangan kiri dan tangan kanan untuk menghasilkan 1 unit dompet membutuhkan waktu sebesar 59.17 menit.

Setelah dilakukan perhitungan selisih waktu antara proses kerja diperusahaan saat ini dengan proses kerja usulan dengan pendekatan peta tangan kiri dan tangan kanan diperoleh penghematan waktu sebesar 10.18 menit, dengan prosentase penghematan waktu baku pada proses marking dan pemotongan sebesar $11.25 \%$, proses pengeleman sebesar $20.69 \%$ dan proses jahit sebesar $7.39 \%$, serta prosentase kenaikan outputstandart sebesar 21.43\%. Maka dapat diketahui bahwa tingkat produktifitas yang paling optimal dalam membuat dompet adalah menggunakan proses kerja usulan dengan pendekatan peta tangan kiri dan tangan kanan.

\section{DAFTAR PUSTAKA}

Kharisma, Saputra. 2009. Menentukan waktu baku produksi dan perancangan kerja dengan menggunakan peta tangan kiri dan tangan kanan di PD. Sandang Jaya.

Sutalaksana dan Tjakraatmaja. 1997. Teknik Tata Cara Kerja. Departemen Teknik Industri Bandung.

Suryabrata, S. (2013).Metode penelitian.Jakarta: Rajawali Pers.

Wingnjosoebroto, Sritomo. 2003. Ergonomi, Studi Waktu, dan pengukuran kerja, Institut Teknologi sepuluh November, Surabaya. 
